\title{
Temperatura e substrato para germinação de sementes de flor-de-maio (Schlumbergera truncata (Haw.) Moran)
}

\author{
Alessandro Borini Lone ${ }^{1}$, Gilberto Rostirolla Batista de Souza ${ }^{2}$, Karen Sinéia de Oliveira ${ }^{3}$, Lucia Assari Sadayo \\ Takahashi ${ }^{4}$, Ricardo Tadeu de Faria ${ }^{5}$
}

\section{RESUMO}

Schlumbergera truncata é uma cactácea de hábito epífito conhecida popularmente como flor-de-maio ou flor-deseda. É uma planta ornamental, cultivada em vasos e muito apreciada pela beleza de suas flores. O objetivo deste trabalho foi avaliar o efeito da temperatura e do substrato na germinação de sementes de S. truncata. Os substratos utilizados no experimento foram: papel mata-borrão, areia de granulação média, casca de arroz carbonizada e bagaço de cana triturado, e as temperaturas avaliadas foram 20 , 25 e $30{ }^{\circ} \mathrm{C}$. As variáveis analisadas foram: porcentagem de germinação, índice de velocidade de germinação e tempo médio de germinação. As maiores porcentagens de germinação ocorreram em 20 e $25^{\circ} \mathrm{C}$ em papel, areia e casca de arroz carbonizada. Na casca de arroz carbonizada, observaramse os maiores valores de índice de velocidade de germinação e os menores valores de tempo médio de germinação. Concluiu-se que a temperatura de $20{ }^{\circ} \mathrm{C}$ e o substrato casca de arroz carbonizada foram mais adequados para a germinação de sementes de $S$. truncata e que o bagaço de cana não foi adequado como substrato para a germinação da espécie.

Palavras-chave: Cactaceae, planta ornamental, teste de germinação.

\section{ABSTRACT}

\section{Temperature and substrate for germination of Christmas Cactus (Schlumbergera truncata (Haw.) Moran)}

Schlumbergera truncata is a cacti of epiphytic habit known popularly as Christmas Cactus, Thanksgiving Cactus or Crab Cactus, Zygocactus. It is an ornamental plant cultivated in vases and highly appreciated for the beauty of their flowers. The objective of this work was to evaluate the effect of temperature and of substrate on seed germination of S. truncata. The substrates used in the experiment included: blotting paper, sand of medium granulation, charred rice peel and triturated cane pulp. The tested temperatures were 20,25 and $30^{\circ} \mathrm{C}$. The analyzed variables were: germination percentage, index of germination speed and average germination time. The highest germination percentages were recorded at $20^{\circ} \mathrm{C}$ and $25^{\circ} \mathrm{C}$ for paper, sand and charred rice peel. Charred rice peel showed the highest index of germination speed and the lowest average germination time. In conclusion, temperature at $20^{\circ} \mathrm{C}$ and the substrate charred rice peel showed the best results for seed germination of S. truncata and cane pulp was not a suitable substrate for the germination of the species.

Key words: Cactaceae, germination test, ornamental plants.

\footnotetext{
Recebido para publicação em junho de 2009 e aprovado em abril de 2010

${ }^{1}$ Biólogo, Mestre. Doutorando em Agronomia, Departamento de Agronomia, Universidade Estadual de Londrina (UEL), Caixa Postal 6001, 86051-990, Londrina, Paraná (PR), Brasil. alone_bio@yahoo.com.br

2 Engenheiro-Agrônomo. Mestrando em Fitotecnia, Departamento de Agronomia, UEL, Caixa Postal 6001, 86051-990, Londrina, PR. gilberto.rostirolla@gmail.com

${ }^{3}$ Graduanda em Agronomia. UEL, Caixa Postal 6001, 86051-990, Londrina, PR. karynkimberly@hotmail.com

${ }^{4}$ Engenheira-Agrônoma, Doutora. Departamento de Agronomia, UEL, Caixa Postal 6001, 86051-990, Londrina, PR. sadayo@eu.br

${ }^{5}$ Engenheiro-Agrônomo, Doutor. UEL, Caixa Postal 6001, 86051-990, Londrina, PR. faria@uel.br
} 


\section{INTRODUÇÃO}

As espécies do gênero Schlumbergera ocorrem nos Estados do Espírito Santo, Rio de Janeiro, São Paulo e Minas Gerais. É conhecido popularmente como flor-demaio ou flor-de-seda. Trata-se de cactáceas de hábito epífito com filocládios achatados e dentados (Paula \& Ribeiro, 2004).

A espécie Schlumbergera truncata (Haw.) Moran apresenta filocládios suculentos, pendentes e sem espinhos, e pode atingir de 30 a $60 \mathrm{~cm}$ de altura e flores que se concentram na extremidade dos filocládios. É uma planta ornamental, cultivada em vasos e muito apreciada pela beleza de suas flores (Lorenzi \& Souza, 2001). A espécie apresenta autoincompatibilidade e, por isso, sua polinização é, obrigatoriamente, cruzada (Boyle, 1996; Salla \& Figueiredo, 2004).

As sementes de diferentes espécies apresentam comportamento germinativo variável para a temperatura, o que pode fornecer informações de interesse biológico e ecológico (Labouriau, 1983). Em diversos trabalhos foi verificado que a temperatura ótima para germinação de semente de cactos é, normalmente, em torno de $25{ }^{\circ} \mathrm{C}$ (Nobel, 1988; Rojas-Aréchiga \& Vázquez-Yanes, 2000; Lone et al., 2007), variando de $15^{\circ} \mathrm{C}$ para o cacto colunar Oreocereus trolii (Zimmer 1969, citado por De La Barrera \& Nobel, 2003) a $33^{\circ} \mathrm{C}$ para Pereskia aculeata (Dau \& Labouriau, 1974), um cacto com folhas e porte primitivo.

Estudos sobre a influência da temperatura na germinação das sementes são essenciais para entender os aspectos ecofisiológicos e bioquímicos desse processo (Labouriau, 1983; Bewley \& Black, 1994). Seus efeitos podem ser avaliados a partir de mudanças ocasionadas na porcentagem, velocidade e frequência relativa de germinação ao longo do tempo de incubação (Labouriau \& Pacheco, 1978).

Os substratos também apresentam grande influência nos testes de germinação, pois fatores como aeração, estrutura, capacidade de retenção de água e grau de infestação por patógenos podem variar de um substrato para outro, favorecendo ou prejudicando a germinação das sementes (Popinigis, 1985). Na escolha do substrato, devem ser considerados o tamanho da semente, sua exigência em relação à umidade, sensibilidade ou não à luz e a facilidade que esse oferece para o desenvolvimento e a avaliação das plântulas (Figliolia et al., 1993).

Dentre os substratos mais utilizados e prescritos em Brasil (1992) estão: o papel, a areia e o solo; entretanto, podem ser encontrados no mercado substratos alternativos que já estão sendo utilizados em testes e pesquisas na área florestal, como o pó-de-coco (Pacheco et al., 2006), a casca de arroz carbonizada (Stringheta et al., 2005) e a vermiculita (Silva \& Aguiar, 2004; Lopes \& Pereira, 2005;
Hirano \& Possamai, 2008). Outro substrato que vem sendo empregado para a germinação de sementes e produção de mudas de hortaliças, frutíferas e florestais é o bagaço de cana, carbonizado ou não (Biasi et al., 1995; Toledo et al., 1997; Cunha et al., 2005).

O objetivo deste trabalho foi avaliar o efeito da temperatura e do substrato na germinação de sementes de $S$. truncata.

\section{MATERIAL E MÉTODOS}

Foram utilizadas no teste de germinação sementes de $S$. truncata, da variedade vermelha, provenientes de frutos colhidos no período de maio a junho de 2008, em coleções particulares da região de Londrina, Paraná. As sementes foram retiradas dos frutos, lavadas em água corrente e secas à sombra sobre folhas de papel-filtro por 48h, para posterior homogeneização e armazenamento em câmara fria (6 - $9^{\circ} \mathrm{C}$ e $75 \%$ U.R.), em embalagem de polietileno, até a instalação do teste que ocorreu após 15 dias.

Os substratos utilizados no experimento foram: papel mata-borrão, areia de granulação média, casca de arroz carbonizada (CAC) e bagaço de cana triturado. Os substratos, à exceção do papel, foram postos para secar em estufa com ventilação forçada a $65^{\circ} \mathrm{C}$ por 24 h. Após a secagem, foram acondicionados em caixas de plástico transparente com tampa $(11 \times 11 \times 3,5 \mathrm{~cm})$ até a metade do volume da caixa, e para o papel, foi usado uma folha por caixa.

O papel foi umedecido com água destilada na quantidade de 2,5 vezes a massa do papel não hidratado. Os demais substratos foram umedecidos a $60 \%$ da capacidade máxima de retenção de água. Após o umedecimento, foram colocadas 50 sementes por caixa e mantidas em germinadores com temperaturas de 20, 25 e $30{ }^{\circ} \mathrm{C}$ em sala de crescimento com iluminação de 1.200 lux e fotoperíodo de $10 \mathrm{~h}$.

O delineamento experimental foi inteiramente casualizado, com arranjo experimental do teste de germinação constituindo em esquema fatorial de $3 \times 4$, composto de três temperaturas e quatro substratos, com quatro repetições por tratamento e 50 sementes por repetição.

A avaliação do teste de germinação foi feita diariamente durante 30 dias, e foram consideradas germinadas as sementes que apresentaram emissão do hipocótilo. As variáveis avaliadas foram: porcentagem de germinação, índice de velocidade de germinação (IVG), que foi calculado de acordo com a fórmula de Maguirre (1962) descrita no trabalho de Nakagawa (1994), e tempo médio de germinação (dias), calculado segundo Lima et al. (2006).

Os valores de porcentagem de germinação foram transformados em arco seno (x/100) $)^{0,5}$ para sua normalização e, 
assim como para os demais valores, submetidos à análise de variância, e as médias, comparadas pelo teste de Tukey a 5\% de significância.

\section{RESULTADOS E DISCUSSÃO}

Entre as temperaturas, as maiores porcentagens de germinação ocorreram em 20 e $25^{\circ} \mathrm{C}$ em papel, areia e CAC, e na casca de arroz as porcentagens não apresentaram diferenças estatísticas entre 25 e $30^{\circ} \mathrm{C}$. Para o bagaço de cana, a maior porcentagem foi observada em $20{ }^{\circ} \mathrm{C}$ (Tabela 1 ).

Esse resultado está de acordo com Bachthaler (1990), que obteve elevada germinação (100\%) de sementes de $S$. truncata em temperaturas entre 20 e $25^{\circ} \mathrm{C}$ utilizando areia como substrato. No entanto, Simão et al. (2007) verificaram que a temperatura ótima para a germinação do cacto epífito Hylocereus setaceus (Salm-Dyck) Ralf Bauer está entre 25 e $30^{\circ} \mathrm{C}$.

Foi verificado em diversos trabalhos que a temperatura ótima para germinação de semente de cactos é, normalmente, em torno de $25^{\circ} \mathrm{C}$ (Nobel, 1988; Rojas-Aréchiga \& Vázquez-Yanes, 2000; Lone et al., 2007).

Andrade et al. (2008) em seu trabalho com germinação de sementes do cacto pitaya (Hylocereus undatus (Haw.) Britton \& Rose) em diferentes substratos, obtiveram bons resultados em papel, porém não ocorreu o mesmo com o substrato areia. No entanto, Lone et al. (2007), trabalhando com germinação de sementes de Melocactus bahiensis (Britton \& Rose) Luetzelb., obtiveram bons resultados utilizando areia como substrato na germinação. A areia também foi o substrato padrão para a germinação de diversas espécies de cactos utilizados por Cavalcanti \& Resende (2007).

Pelos resultados, observa-se que as porcentagens de germinação a $20^{\circ} \mathrm{C}$ e $25{ }^{\circ} \mathrm{C}$ no substrato bagaço de cana (33 e 5\%, respectivamente) foram inferiores em relação àquelas observadas nos demais substratos. Em $30^{\circ} \mathrm{C}$, as sementes em bagaço de cana e papel apresentaram os menores valores de porcentagem de germinação em relação àquelas em areia e CAC (Tabela 1).

Biasi et al. (1995) também obtiveram baixa porcentagem de germinação de maracujá amarelo utilizando bagaço de cana como substrato. No entanto, o mesmo mostrou bons resultados quando misturado com turfa na proporção de $1: 1\left(\mathrm{v}^{-1} \mathrm{~V}^{-1}\right)$.

De acordo com a Figura $1 \mathrm{~A}$, a temperatura de $20{ }^{\circ} \mathrm{C}$ apresentou o melhor resultado para porcentagem média acumulada de germinação (74\%), seguida do resultado obtido a $25^{\circ} \mathrm{C}$ (65\%). O início da germinação das sementes nessas temperaturas ocorreu no quinto dia, e na temperatura de $30^{\circ} \mathrm{C}$, a partir do sétimo dia. A estabilização da germinação ocorreu após o 21 dias para a temperatura de $20^{\circ} \mathrm{C}, 22$ dias para $25^{\circ} \mathrm{C}$ e após o 26 dias para $30^{\circ} \mathrm{C}$.

Em relação aos substratos, a Figura 1B mostra que a CAC apresentou o melhor resultado para a porcentagem média acumulada de germinação (86\%) em relação aos demais. Observa-se também que a cana teve resultado inferior em relação aos demais substratos (32\%). O início da germinação em CAC ocorreu a partir do quinto dia, a partir do sexto dia em areia, sétimo em papel e oitavo em cana. A estabilização da germinação ocorreu aos 23 dias para CAC, 23 para papel e cana e 24 em areia.

Leal et al. (2007) obtiveram início de germinação das sementes de quatro variedades de flor-de-maio, em diferentes substratos, no quinto dia após a semeadura, porém em condições de casa de vegetação, e Lone et al. (2009), trabalhando com germinação de sementes de duas espécies de cactos epífitos (Rhipsalis floccosa Salm-Dyck ex Pfeiff. e Rhipsalis pilocarpa Loefgr.), também obtiveram os melhores resultados em CAC.

Na CAC, foram observados os maiores valores de índice de velocidade de germinação (IVG) em relação aos demais substratos nas três temperaturas testadas. Os menores valores de IVG foram observados no bagaço de cana nas três temperaturas testadas. Não houve diferen-

Tabela 1. Porcentagem de germinação (\%G), índice de velocidade de germinação (IVG) e tempo médio de germinação (TM, dias) de sementes de Schlumbergera truncata em diferentes temperaturas $\left({ }^{\circ} \mathrm{C}\right)$ e substratos. Londrina, PR, 2008

\begin{tabular}{|c|c|c|c|c|c|c|c|c|c|}
\hline \multirow{2}{*}{ Substrato $^{2}$} & \multicolumn{3}{|c|}{$\% \mathrm{G}^{1}$} & \multicolumn{3}{|c|}{ IVG } & \multicolumn{3}{|c|}{$\mathbf{T M}$} \\
\hline & $20^{\circ} \mathrm{C}$ & $25^{\circ} \mathrm{C}$ & $30^{\circ} \mathrm{C}$ & $20^{\circ} \mathrm{C}$ & $25^{\circ} \mathrm{C}$ & $30^{\circ} \mathrm{C}$ & $20^{\circ} \mathrm{C}$ & $25^{\circ} \mathrm{C}$ & $30^{\circ} \mathrm{C}$ \\
\hline Papel $^{2}$ & $86 \mathrm{Aa}^{3}$ & $80 \mathrm{Aa}$ & $3 \mathrm{Cb}$ & 4,61 Ba & 4,11 Ca & $0,11 \mathrm{Cb}$ & $10,81 \mathrm{Ab}$ & $11,12 \mathrm{Bb}$ & $15,50 \mathrm{Aa}$ \\
\hline Areia & 85 Аа & 86 Аа & $47 \mathrm{Bb}$ & $4,80 \mathrm{Bb}$ & $5,82 \mathrm{Ba}$ & $1,62 \mathrm{Bc}$ & $9,99 \mathrm{ABb}$ & 8,17 BCb & $15,49 \mathrm{Aa}$ \\
\hline Cana & $33 \mathrm{Ba}$ & $5 \mathrm{Bb}$ & $1 \mathrm{Cb}$ & $1,55 \mathrm{Ca}$ & $0,25 \mathrm{Db}$ & $0,02 \mathrm{Cb}$ & $12,30 \mathrm{Ab}$ & $16,58 \mathrm{Aa}$ & $11,00 \mathrm{Bb}$ \\
\hline CAC & $91 \mathrm{Aa}$ & $88 \mathrm{Aab}$ & $78 \mathrm{Ab}$ & 6,93 Аа & 7,52 Aa & 3,32 Ab & 7,05 Bb & $6,27 \mathrm{Cb}$ & $12,67 \mathrm{ABa}$ \\
\hline CV (\%) & & 13,71 & & & 13,65 & & & 15,53 & \\
\hline
\end{tabular}

${ }^{1}$ Dados transformados em arco-seno (x/100) ${ }^{0,5}$ somente para efeito de análise estatística. Dados tabelados não-transformados.

${ }^{2}$ Substratos: Papel - Papel mata-borrão; Areia - Areia granulação média; Cana - Bagaço de cana triturado; e CAC - Casca de arroz carbonizada.

${ }^{3}$ Médias seguidas de mesma letra, maiúscula na coluna e minúscula na linha, dentro de cada variável, não diferem entre si pelo teste de Tukey a $5 \%$ de probabilidade. 

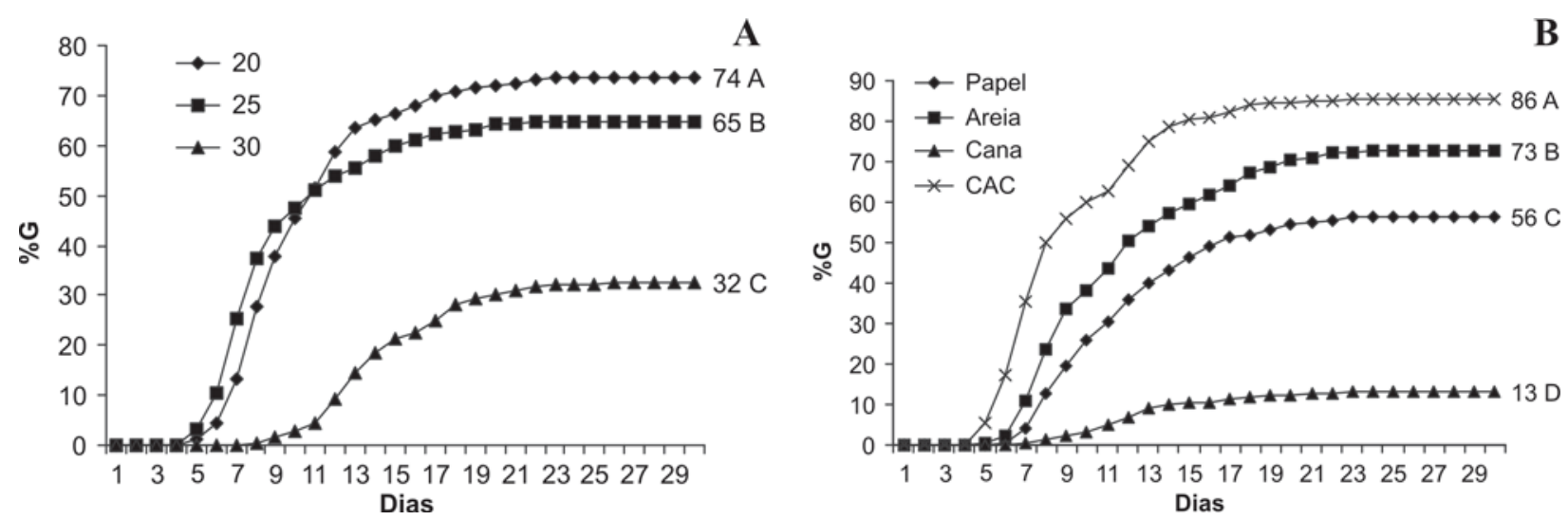

Figura 1. Porcentagem média acumulada de germinação (\%G) de sementes de Schlumbergera truncata em função do tempo (dias) para temperaturas $\left(20,25\right.$ e $\left.30^{\circ} \mathrm{C}\right)$ (A) e para substratos (Papel - Papel mata-borrão; Areia - Areia granulação média; Cana - Bagaço de cana triturado; e CAC - Casca de arroz carbonizada) (B).

Médias seguidas da mesma letra não diferem entre si pelo teste de Tukey a 5\% de probabilidade. CV(\%) = 13,71.

ça nos valores de IVG entre papel e areia a $20^{\circ} \mathrm{C}$; no entanto, nas temperaturas de 25 a $30{ }^{\circ} \mathrm{C}$ a areia apresentou maiores valores de IVG em relação ao papel (Tabela 1).

As sementes em CAC apresentaram os menores valores de tempo médio de germinação (7,05 e 6,27 dias) em relação aos demais substratos nas temperaturas de 20 e $25^{\circ} \mathrm{C}$. Em 30 ${ }^{\circ} \mathrm{C}$, a germinação em casca de arroz não apresentou diferença estatística em relação aos outros substratos (Tabela 1).

Além dos resultados obtidos, a CAC mostrou ser eficiente para o teste de germinação por ser leve, facilitando o manuseio, ter coloração escura (preta), que serve de contraste, facilitando a verificação da germinação das sementes, pois as plântulas apresentam coloração verdeclara; e por não ter sido constatado o surgimento de contaminações por microrganismos. Klein et al. (2002) afirmaram que a CAC melhora a disponibilidade de água e a porosidade de aeração, auxiliando o processo germinativo.

A $20{ }^{\circ} \mathrm{C}$ os substratos papel, areia e bagaço de cana não apresentaram diferença estatística entre si no tempo médio de germinação. A $25{ }^{\circ} \mathrm{C}$ o bagaço de cana teve o maior valor de tempo médio de germinação (16,58 dias), caracterizando germinação mais tardia. No entanto, a 30 ${ }^{\circ} \mathrm{C}$ o bagaço de cana apresentou tempo médio de germinação inferior ao papel e à areia (11 dias) (Tabela 1).

Os substratos papel, areia e CAC apresentaram elevação dos valores do tempo médio de germinação a $30^{\circ} \mathrm{C}$ em relação as temperaturas de 20 e $25{ }^{\circ} \mathrm{C}$ (Tabela 1). Relação contrária foi observada por Lone et al. (2007) em Melocactus bahiensis, no qual os valores de tempo médio de germinação tiveram decréscimo conforme o aumento da temperatura de 20 para $30^{\circ} \mathrm{C}$.

Durante o teste de germinação observou-se escurecimento do bagaço de cana seguido do aparecimento de cheiro forte, possivelmente ocasionado por microrganismos que podem ter interferido de modo negativo na germinação das sementes.

\section{CONCLUSÕES}

A casca de arroz carbonizada foi o substrato mais indicado para germinação de sementes de Schlumbergera truncata.

A temperatura de $20{ }^{\circ} \mathrm{C}$ foi a mais adequada para sua germinação.

\section{REFERÊNCIAS}

Andrade RA, Oliveira IVM, Silva MTH \& Martins ABG (2008) Germinação de pitaya em diferentes substratos. Revista Caatinga, 21:71-75.

Bachthaler E (1990) Christmas cacti. Deut Gartenbau, 44:2826-2828.

Bewley JD \& Black M (1994) Seeds: physiology of development and germination. 2 ed. New York, Plenum Press. 445p.

Biasi LA, Bilia DAC, São José AR, Fornasieri JL \& Minam K (1995) Efeito de misturas de turfa e bagaço de cana sobre a produção de mudas de maracujá e tomate. Scientia Agricola, 52:239-243

Boyle TH (1996) Characteristics of self-incompatibility in Schlumbergera truncata x S. buckleyi (Cactaceae). Sexual Plant Reproduction, 9:49-53.

Brasil (1992) Ministério da Agricultura e Reforma Agrária. Regras para análise de sementes. Brasília, SNDA/DNDV/CLAV. 365p.

Cavalcanti NB \& Resende GM (2007) Efeito de diferentes substratos no desenvolvimento de mandacaru (Cereus jamacaru p. Dc.), facheiro (Pilosocereus pachycladus Ritter), xiquexique (Pilosocereus gounellei (A. Webwr ex K. Schum.) Bly. Ex Rowl.) e coroa-de-frade (Melocactus bahiensis Britton \& Rose). Revista Caatinga, 20:28-35.

Cunha AO, Andrade LA, Bruno RLA, Silva JAL \& Souza VC (2005) Efeitos de substratos e das dimensões dos recipientes na qualidade das mudas de Tabebuia impetiginosa (Mart. Ex D.C.) Standl. Revista Árvore, 29:507-516.

Dau L \& Labouriau LG (1974) Temperature control of seed germination in Pereskia aculeata Mill. Anais Academia Brasileira de Ciências, 46:311-322.

De La Barrera E \& Nobel PS (2003) Physiological ecology of seed germination for the columnar cactus Stenocereus queretaroensis. Journal of Arid Environments, 53:297-306. 
Figliolia MB, Oliveira EC \& Piña-Rodrigues FCM (1993) Análise de sementes. In: Aguiar IB, Piña-Rodrigues FCM \& Figliolia MB (Coord.) Sementes florestais tropicais. Abrates, p.137-174.

Hirano E \& Possamai E (2008) Estádio de maturação do fruto e germinação de sementes de três espécies de Lauraceae. Scientia Agraria, 9:219-223.

Klein VA, Camara RK, Simon MA \& Dias ST (2002) Casca de arroz carbonizada como condicionador de substrato. In: Furlani AMC et al. (Coord.) Caracterização, manejo e qualidade de substratos para produção de plantas. Campinas, Instituto Agronômico, 95p. (Documentos IAC, 70)

Labouriau LG \& Pacheco A (1978) On the frequency of isothermal germination in seeds of Dolichos biflorus L. Plant \& Cell Physiology, 19:507-512.

Labouriau LG (1983) A germinação de sementes. Washington, OEA. 174p.

Leal L, Biondi D \& Nunes JRS (2007) Propagação por sementes de Schlumbergera truncata (Haw.) Moran (flor-de-maio) em diferentes substratos. Acta Scientiarum Biological Sciences, 29:277-280.

Lima JD, Almeida CC, Dantas VAV, Siba BM \& Moraes WS (2006) Efeito da temperatura e do substrato na germinação de sementes de Caesalpinia ferrea Mart. ex Tul. (Leguminosae, Caesalpinoideae). Revista Árvore, 30:513-518.

Lone AB, Takahashi LSA, Faria RT \& Unemoto LK (2007) Germinação de Melocactus bahiensis (Cactaceae) em diferentes substratos e temperaturas. Scientia Agraria, 8:365-369.

Lone AB, Molo CX, Takahashi LSA \& Unemoto LK (2009) Germinação de sementes de Rhipsalis em diferentes substratos. Scientia Agraria, 10:419-422.

Lopes JC \& Pereira MD (2005) Germinação de sementes de cubiu em diferentes substratos e temperaturas. Revista Brasileira de Sementes, 27:146-150.

Lorenzi H \& Souza HM (2001) Plantas ornamentais no Brasil: arbustivas, herbáceas e trepadeiras. 3. ed. Nova Odessa, Instituto Plantarum. 558p.
Nakagawa J (1994) Testes de vigor baseados na avaliação das plântulas. In: Vieira RD \& Carvalho NM (Eds.) Testes de vigor em sementes. Funep, Jaboticabal. p.49-85.

Nobel PS (1988) Environmental biology of agaves and cacti. New York, Cambridge University Press. 270p.

Pacheco MV, Matos VP, Ferreira RLC, Feliciano ALP \& Pinto KMS (2006) Efeito de temperaturas e substratos na germinação de sementes de Myracrodruon urundeuva Fr. All. (Anacardiaceae). Revista Árvore, 30:359-367.

Paula CC \& Ribeiro OBC (2004) Cultivo prático de cactáceas. Viçosa, UFV. 94p.

Popinigis F (1985) Fisiologia de sementes. 2.ed. Brasília, Agiplan. 289p.

Rojas-Aréchiga M \& Vázquez-Yanes C (2000) Cactus seed germination: a review. Journal of Arid Environments, 44:85-104.

Salla VR \& Figueiredo RA (2004) Breeding system in Schlumbergera truncata (Haw.) Mor. (Cactaceae), Jundiaí, SP. Bioikos, 18:35-38.

Silva LMM \& Aguiar IB (2004) Efeito dos substratos e temperaturas na germinação de sementes de Cnidosculus phyllacanthus Pax \& k. Hoffm. (faveleira). Revista Brasileira de Sementes, 26:9-14.

Simão E, Socolowski F \& Takaki M (2007) The epiphytic Cactaceae Hylocereus setaceus (Salm-Dick ex DC.) Ralf Bauer seed germination is controlled by light and temperature. Brazilian Archives of Biology and Technology, 50:655-662.

Stringheta ACO, Silva DJH, Cardoso AA, Fontes LEF \& Barbosa JG (2005) Germinação de sementes e sobrevivência das plântulas de Tillandsia geminiflora Brongn, em diferentes substratos. Acta Scientiarum. Agronomy, 27:165-170.

Toledo ARM, Girotto LF \& Souza M (1997) Efeito de substratos na formação de laranjeira (Citrus cinessis (L) Osbeack cv. Pêra Rio) em vaso. Ciência e Agrotecnologia, 21:29-34. 